Diospyros crassiflora was listed as vul-

Micropropagation and Effect of Phloroglucinol on Rooting of Diospyros crassiflora Hiern

\author{
Alvine Ornella Tchouga
}

International Institute of Tropical Agriculture (IITA), BP 2008 (Messa), Yaounde, Cameroon; Laboratory of Plant Physiology, Higher Teacher Training College, University of Yaounde I, P.O. Box 47, Yaounde, Cameroon

\section{Vincent Deblauwe}

International Institute of Tropical Agriculture (IITA), BP 2008 (Messa), Yaounde, Cameroon; Center for Tropical Research, Institute of the Environment and Sustainability, University of California Los Angeles, Los Angeles, CA 90095

\section{Stephanie Astride Mouafi Djabou \\ Laboratory of Plant Physiology, Higher Teacher Training College, University of Yaounde I, P.O. Box 47, Yaounde, Cameroon}

\section{Giovanni Forgione}

International Institute of Tropical Agriculture (IITA), BP 2008 (Messa), Yaounde, Cameroon

\section{Rachid Hanna \\ International Institute of Tropical Agriculture (IITA), BP 2008 (Messa), Yaounde, Cameroon}

\section{Nicolas Niemenak \\ Laboratory of Plant Physiology, Higher Teacher Training College, University of Yaounde I, P.O. Box 47, Yaounde, Cameroon}

Additional index words. African rainforest ebony, in vitro culture, microcutting, plant growth regulators

\begin{abstract}
The jet-black to streaked ebony wood produced by the African ebony (Diospyros crassiflora Hiern, Ebenaceae) is exploited in Central and West Africa. A conservation effort is currently underway in Cameroon to propagate the tree through seedlings and cuttings. However, the intermittent availability of its seeds and the long time required for rooting formation of cuttings are limiting its propagation. This study aims to develop a successful protocol for ebony micropropagation. In vitro culture of nodal segments from seedlings was performed in half-strength Murashige and Skoog (MS) medium supplemented with either zeatin $(0.0,2.3,4.6,9.1,13.7,18.2,22.8$, and $27.4 \mu \mathrm{M})$ or 6-benzylaminopurine (BAP) $(0.0,2.2,4.4,8.8,13.3,17.8,22.2$, and $26.6 \mu \mathrm{M})$. After 12 weeks, all media allowed shoot budbreak. Shoots displaying the greatest budbreak were observed with $22.8 \mu \mathrm{M}$ zeatin and 22.2 $\mu_{M}$ BAP. The shoots were then transferred to a medium supplemented with indole-3butyric acid (IBA) and phloroglucinol (PG) at different concentrations for root induction. Root induction was observed on the shoots initially induced in the medium with BAP, but not in those grown in the medium with zeatin. In half-strength MS supplemented with 396.5 $\mu M$ PG plus 14.2 $\mu$ M IBA, the formation of a single tap root was observed on $79 \%$ of shoots, with an average root length of $2.8 \pm 0.18 \mathrm{~cm}$. Rooted plants were successfully acclimatized to the greenhouse, with a $\mathbf{5 0 \%}$ survival rate. This is the first report on Diospyros crassiflora micropropagation, which paves the way for rapid ebony multiplication to respond to needed conservation efforts.
\end{abstract}

Diospyros crassiflora H. (Ebenaceae), commercially known as the African ebony, is a small forest tree found at elevations less than $1000 \mathrm{~m}$ in South Nigeria, Cameroon, Central African Republic, Equatorial Guinea, Gabon, Republic of the Congo, and Democratic Republic of the Congo (Lemmens et al., 2012). It is a shade-tolerant species characterized by a relatively low growth rate (Bongjoh and Nsangou, 2001). The hard, dense black heartwood of the tree is exploited in Cameroon and other countries for the construction of musical instruments such as the violin, guitar, cello, contrabass, and piano keys (Lemmens et al., 2012; Taylor, 2012). The species is also used locally for medicinal purposes and pharmacological research, and has proven antifungal and antibacterial properties in stem bark extracts (Dzoyem et al., 2007; Tangmouo et al., 2006). nerable on the International Union for Conservation of Nature Red List because it is threatened by the destruction of forests for agriculture and grazing, and the commercial logging of other species (Schatz et al., 2019). For now, the species has not been included in extended sylvicultural or agroforestry systems. As part of the Congo Basin Institute's ebony conservation project, an integrated agroforestry model is currently being developed to compensate for the decrease of tree populations. The development of a costeffective, reliable approach to large-scale production of the plant is becoming essential for long-term sustainability of the species.

Until now, propagation by seeds has been the main form of propagation of $D$. crassiflora. However, seed production is seasonal and year dependent. Moreover, reproduction through seeds does not allow genetic fidelity because of its heterozygosity. Vegetative propagation by leafy stem cutting is feasible, but the quantity of plant material available from a selected donor plant is limited and the cuttings maintain the plagiotropic growth of the lateral stem of the cutting (Tsobeng et al., 2011). Our study aimed at developing a protocol of ebony micropropagation that might circumvent the shortcomings of both seedling and cutting propagation.

Micropropagation of the close relatives $D$. virginiana (Palla et al., 2013) and D. kaki (Mitrofanova and Mitrofanova, 2004; Pijut, 2012) has shown that the development of axillary buds could be induced by cytokinin. PG is a phenolic compound known for its properties as a promoter of plant growth (Teixeira da Silva et al., 2013). The objective of this study was to investigate the effect of cytokinins on the development of axillary buds, and PG on root initiation of $D$. crassiflora.

\section{Materials and Methods}

Plant material and source of explant. Mature seeds were harvested on 35-year-old D. crassiflora trees in Ekombite, Central Region, Cameroon (lat. $3^{\circ} 16^{\prime} \mathrm{N}$, long. $\left.11^{\circ} 19^{\prime} \mathrm{E}\right)$. Voucher specimens of one mother plant (V. Deblauwe no. 376) were deposited at the herbaria of the Higher Teacher Training College, University of Yaounde I, Yaounde, Cameroon; Université Libre de Bruxelles, Belgium; and the Missouri Botanical Garden, St. Louis, MO. The seeds were germinated and maintained in a shade house at the International Institute of Tropical Agriculture campus in Yaounde, Cameroon. Germination was conducted on moist Whatman paper $\mathrm{n}^{\circ} 3$ (GE Healthcare Bio-Sciences, Pittsburgh, PA) in a $500-\mathrm{mL}$ plastic culture vessel for 2 weeks. Each vessel, containing 10 seeds, was incubated in a growth chamber at $25 \pm 1{ }^{\circ} \mathrm{C}$ with an irradiance of $40 \mu \mathrm{mol} \cdot \mathrm{m}^{-2} \cdot \mathrm{s}^{-1}$ provided by cool white fluorescent tubes ( $40 \mathrm{~W}$, Philips) with a 16-h photoperiod. After germination, seedlings were subcultured in plastic bags $(100 \mathrm{~mm} \times 150 \mathrm{~mm} \times 50 \mu \mathrm{m})$ containing a mixture of sterilized black soil and river sand 
Table 1. Effect of zeatin and 6-benzylaminopurine (BAP) on shoot formation from nodal explants of D. crassiflora after 12 weeks of culture in half-strength MS medium.

\begin{tabular}{|c|c|c|c|c|c|c|}
\hline $\begin{array}{l}\text { Plant growth } \\
\text { regulators }(\mu \mathrm{M})\end{array}$ & Budbreaking (\%) & $\begin{array}{l}\text { Mean no. of } \\
\text { leaves/shoot }\end{array}$ & $\begin{array}{c}\text { Mean no. of } \\
\text { shoots/explant }\end{array}$ & $\begin{array}{l}\text { Explant with more } \\
\text { than one shoot (\%) }\end{array}$ & Shoot length $(\mathrm{cm})$ & Callus formation (\%) \\
\hline \multicolumn{7}{|l|}{ Zeatin } \\
\hline 2.3 & 87 & $4.7 \pm 0.4 \mathrm{~b}$ & $0.9 \pm 0.1 \mathrm{~b}$ & 0 & $2.9 \pm 0.2 \mathrm{ab}$ & 17 \\
\hline 9.1 & 92 & $5.3 \pm 0.4 \mathrm{ab}$ & $0.9 \pm 0.1 \mathrm{~b}$ & 0 & $2.1 \pm 0.1 \mathrm{c}$ & 14 \\
\hline 13.7 & 91 & $4.8 \pm 0.5 \mathrm{~b}$ & $1.0 \pm 0.0 \mathrm{~b}$ & 6 & $2.0 \pm 0.1 \mathrm{c}$ & 18 \\
\hline 18.2 & 91 & $6.1 \pm 0.5 \mathrm{ab}$ & $1.2 \pm 0.1 \mathrm{ab}$ & 15 & $2.4 \pm 0.1 \mathrm{bc}$ & 18 \\
\hline \multicolumn{7}{|l|}{ BAP } \\
\hline 2.2 & 78 & $5.2 \pm 1.0 \mathrm{~b}$ & $1.7 \pm 0.3 \mathrm{ab}$ & 24 & $1.9 \pm 0.1 \mathrm{a}$ & 0 \\
\hline 4.4 & 86 & $5.0 \pm 0.8 \mathrm{~b}$ & $1.9 \pm 0.3 \mathrm{c}$ & 33 & $1.8 \pm 0.1 \mathrm{a}$ & 0 \\
\hline 8.8 & 85 & $5.7 \pm 0.6 \mathrm{ab}$ & $2.2 \pm 0.3 \mathrm{c}$ & 53 & $1.7 \pm 0.1 \mathrm{a}$ & 0 \\
\hline 13.3 & 87 & $6.7 \pm 0.7 \mathrm{~b}$ & $2.4 \pm 0.3 \mathrm{c}$ & 72 & $2.0 \pm 0.1 \mathrm{a}$ & 0 \\
\hline 17.8 & 85 & $6.2 \pm 0.7 \mathrm{ab}$ & $2.7 \pm 0.4 \mathrm{bc}$ & 64 & $1.9 \pm 0.1 \mathrm{a}$ & 0 \\
\hline 22.2 & 92 & $7.0 \pm 0.8 \mathrm{a}$ & $3.1 \pm 0.3 \mathrm{a}$ & 78 & $1.9 \pm 0.1 \mathrm{a}$ & 0 \\
\hline
\end{tabular}

Values represent means \pm SE. Lower case letters indicate significant differences within each treatment according to Tukey's honestly significant difference test $(P \leq 0.05)$.

$(1: 1, \mathrm{v} / \mathrm{v})$. Plantlets were allowed to grow in a nonmist propagator [developed by Leakey et al. (1990)] installed in a shade house with a shadecloth ( $88 \%$ shade protection, ultraviolet stable polypropylene, water permeable for rainfall and irrigation).

Cuttings from seedlings were used to establish a protocol that will be later extended to cuttings derived from mature trees with good commercial characteristics (i.e., size of the black wood). Cuttings with a length of 0.5 to $1 \mathrm{~cm}$ with a single internode were harvested from 6-month-old seedlings and used as explants. The explants were washed under running tap water for $30 \mathrm{~min}$, followed by treatment with $0.3 \%(\mathrm{w} / \mathrm{v})$ of Banko ${ }^{\circledR}$ Plus (Arysta LifeScience, Paris, France) fungicide; a suspension of $550 \mathrm{~g} \cdot \mathrm{L}^{-1}$ chlorothalonil and $100 \mathrm{~g} \cdot \mathrm{L}^{-1}$ carbendazim for $20 \mathrm{~min}$. Explants were rinsed three times with sterile distilled water in a laminar flow hood and were disinfected successively with $0.1 \%$ (w/v) mercuric chloride solution for $10 \mathrm{~min}$ and $50 \%$ commercial bleach $(2.4 \%$ sodium hypochlorite) containing $0.1 \%$ Tween 80 for $20 \mathrm{~min}$. Last, they were rinsed three times with sterile distilled water. Shoot segments (length, $0.5-1.0 \mathrm{~cm}$ ) containing single nodes were excised from the surface-sterilized materials and used as explants. The explants were cultured in glass culture tubes $(20 \times$

\footnotetext{
Received for publication 18 Sept. 2019. Accepted for publication 15 Nov. 2019.

Published online 5 March 2020.

This work is part of the Ebony project funded by Bob Taylor, USA. We are very grateful to the Alexander von Humboldt Foundation for equipment donation to support the Laboratory of Plant Physiology at the Higher Teacher Training College, University of Yaounde I (grant for N.N., ref 3.4-1115305-CMR-GF).

N.N. is the corresponding author. E-mail: niemenak@ yahoo.com.

This is an open access article distributed under the $\mathrm{CC}$ BY-NC-ND license (https://creativecommons.org/ licenses/by-nc-nd/4.0/).
}

$150 \mathrm{~mm}$ ) containing $10 \mathrm{~mL}$ medium for shoot outgrowth.

Culture media and culture conditions. The basal medium consisted of halfstrength MS (Murashige and Skoog, 1962) salt solution containing Morel and Wetmore (1951) vitamins and 3.0\% sucrose. For shoot growth, media were solidified with $0.3 \%$ $(\mathrm{w} / \mathrm{v})$ gelrite (Duchefa Biochemie B.V., Haarlem, The Netherlands), whereas for root induction $0.7 \%$ Bacto agar (Liofilchem s.r.l., Roseto degli Abruzzi, Italy) was used. In each successive subculture, the basal medium was supplemented with different concentrations of plant growth regulators (see next section). The $\mathrm{pH}$ of the media was adjusted to 5.8 with $1 \mathrm{~N}$ sodium hydroxide or hydrogen chloride. The media were distributed in test tubes $(10 \mathrm{~mL}$ in each) and autoclaved at $121{ }^{\circ} \mathrm{C}$ at $1.2 \mathrm{~kg} \cdot \mathrm{cm}^{-2}$. The cultures were incubated at $25 \pm 2{ }^{\circ} \mathrm{C}$ in a growth chamber, with an irradiance of $40 \mu \mathrm{mol} \cdot \mathrm{m}^{-2} \cdot \mathrm{s}^{-1}$ provided by cool white fluorescent tubes $(40 \mathrm{~W})$, for a 16-h photoperiod.

Shoot growth. Explants were cultured on the medium described earlier with eight concentrations of cytokinins: zeatin $(0.0,2.3,4.6$, $9.1,13.7,18.2,22.8$, and $27.4 \mu \mathrm{M})$ or BAP $(0.0,2.2,4.4,8.8,13.3,17.8,22.2$, and 26.6 $\mu \mathrm{M})$. Sixty-five, 45 , and 50 explants were used for each concentration of zeatin, BAP, and control, respectively. Explants were transferred to fresh media every 3 weeks. After four subcultures (i.e., 12 weeks), the percentage of plants producing shoots, the number of leaves per explant, the number of shoots per explant, the shoot length, and the rate of callus formation were recorded.

Root induction. Shoots of at least $1.5 \mathrm{~cm}$ in length were sampled and transferred to half-strength MS basal medium designed for root induction and differentiation. The basal medium was supplemented with six concentrations of IBA $(0.0,2.5,4.9,9.8,14.7$, and $19.6 \mu \mathrm{M}$ ), and 0.0 or $396.5 \mu \mathrm{M}$ PG. Twentyfour explants were used for each treatment. The percentage of shoot-forming roots, mean number of roots per shoot, and root length were recorded after 12 weeks of culture in the root induction medium.

Acclimatization. Plantlets were removed from the culture flasks and washed gently to remove all media attached to the roots. They were then transplanted in a sterilized mixture of locally collected black soil and river sand $(1: 1, \mathrm{v} / \mathrm{v})$. The mixture was set in recycled half-liter water plastic bottles cut into two parts. The upper and lower parts served as the lid and pot, respectively. The cultures were incubated at $25 \pm 2{ }^{\circ} \mathrm{C}$ in a growth chamber, with an irradiance of $40 \mu \mathrm{mol} \cdot \mathrm{m}^{-2} \cdot \mathrm{s}^{-1}$ provided by cool white fluorescent tubes $(40 \mathrm{~W})$, for a 16-h photoperiod for 6 weeks. Relative humidity was slowly reduced by gradually removing the lids. Plantlets were transferred to a mini propagator, where they were stored for 2 months. From the mini propagator, they were transferred to black plastic bags containing a sterilized mixture of locally collected black soil and river sand $(1: 1, \mathrm{v} / \mathrm{v})$ and were moved to the shade house. To keep a high humidity level, plants were watered every $3 \mathrm{~d}$. The percentage of surviving plants was recorded after 14 weeks of growth in the propagator.

Statistical analysis. Normality and homoskedasticity of the replicated measurements were verified with the Shapiro-Wilk test and Bartlett and Levene test, respectively. An analysis of variance (ANOVA) was performed with the Agricolae package in $\mathrm{R}$ version 1.09j (Mangiafico, 2015). When the ANOVA indicated statistical significance $(P<0.05)$, Tukey's test for multiple comparisons was used to distinguish the differences among treatments.

\section{Results and Discussion}

Shoot proliferation. The first budbreak was observed on explants after 3 weeks grown in half-strength MS medium supplemented with plant growth regulators (data not shown). After 12 weeks, no shoot induction 
was observed for explants in the control media. Shoot growth, number of shoots and leaves on cuttings, and callus formation on explants were affected by the type and the concentration of cytokinins (Table 1, Fig. 1A).

The greatest percentage of shoot induction $(95 \%)$ was observed in the medium
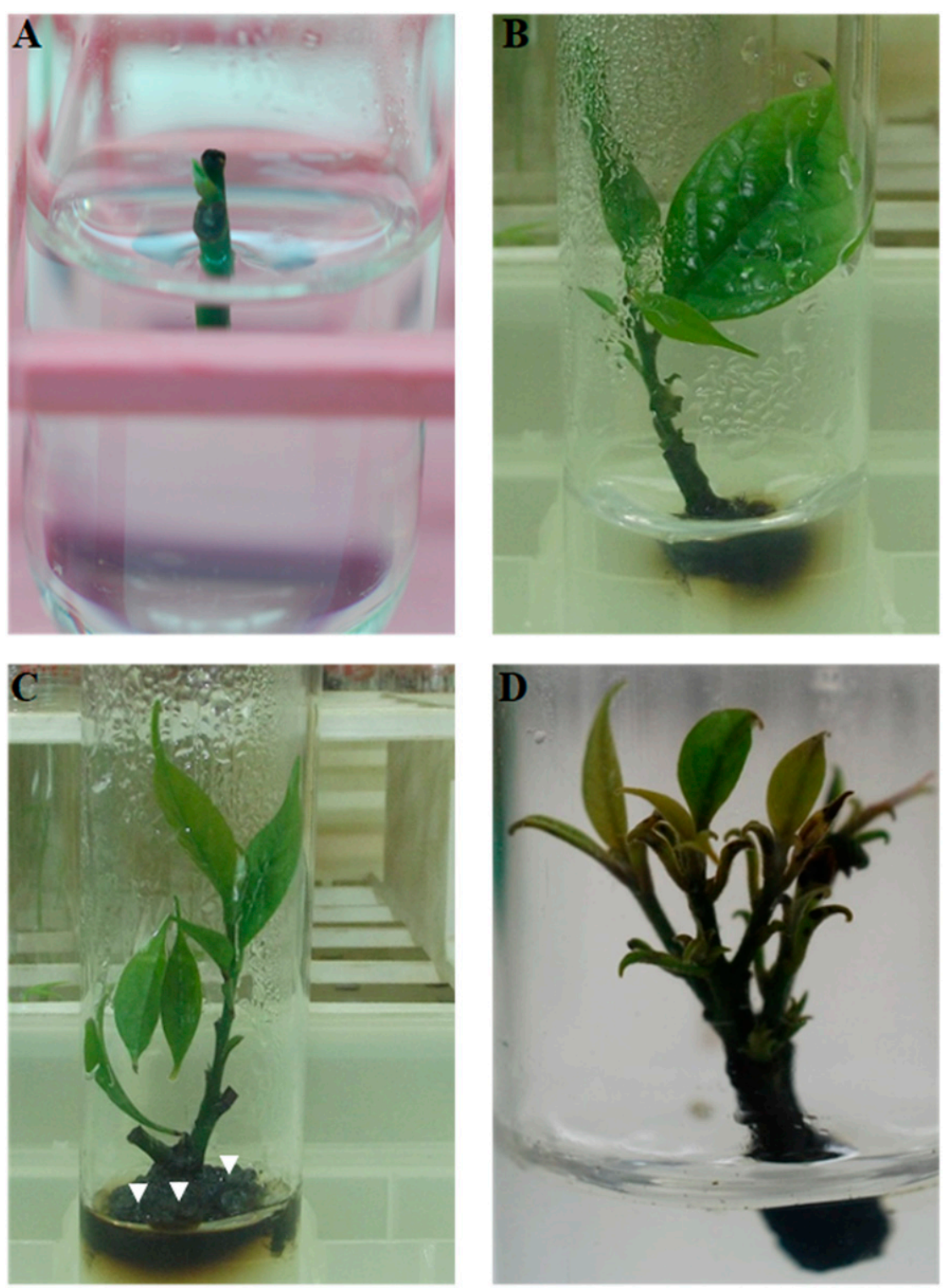

Fig. 1. Shoot induction from explants growing in half-strength MS medium. (A) Budbreaking of explant cultured in $22.8 \mu \mathrm{m}$ zeatin. (B) Shoot elongation of explant cultured in $22.8 \mu \mathrm{M}$ zeatin. (C) Callus formation at the cut extremity of explant cultured in $22.8 \mu \mathrm{m}$ zeatin (arrows). (D) Shoot proliferation in $22.2 \mu \mathrm{M}$ 6-benzylaminopurine.

Table 2. Effect of phloroglucinol and indole-3-butyric acid (IBA) concentrations on root formation of shoot of D. crassiflora after 12 weeks.

\begin{tabular}{lccc}
\hline Phloroglucinol $(\mu \mathrm{M})$ & IBA $(\mu \mathrm{M})$ & Rooting $(\%)$ & Root length $(\mathrm{cm})$ \\
\hline 396.5 & 2.5 & 0 & $0.0 \pm 0.00$ \\
4.9 & 17 & $1.6 \pm 0.14 \mathrm{a}$ \\
& 5.8 & 79 & $1.2 \pm 0.15 \mathrm{a}$ \\
& 14.7 & 71 & $2.8 \pm 0.18 \mathrm{a}$ \\
& 19.6 & $1.1 \pm 0.2 \mathrm{~b}$ \\
\hline
\end{tabular}

Values represent means \pm SE. Different lower case letters indicate significant differences between treatments according to Tukey's test $(P \leq 0.05)$.
BAP stimulated budbreak and multiple shoot regeneration (Fig. 1D). The best shoot proliferation and growth were observed on medium containing $22.2 \mu \mathrm{M}$ BAP. In this treatment, $92 \%$ of the explants displayed budbreak and $78 \%$ of cuttings produced more than one shoot. On average, an explant produced $3.1 \pm 0.3$ shoots with an average length of $1.9 \pm 0.1 \mathrm{~cm}$ (Table 1). Our results support previous findings of the positive effect of zeatin on shoot induction in Diospyros species (Cooper and Cohen, 1985; Fukui et al., 1989; Palla et al., 2013; Tao and Sugiura, 1992). Cooper and Cohen (1985) reported that MS medium with $4.56 \mathrm{~mm}$ or $13.7 \mathrm{~mm}$ zeatin produced the best shoot growth from nodal explants of D. kaki compared with the medium with 6-benzyladenine, kinetin, isopentenyladenine, or benzyltetrahydropyranyl adenine. Fukui et al. (1989) established shoot cultures of 95 Japanese persimmon cultivars on half-strength nitrogen MS medium plus $100 \mathrm{~mm}$ zeatin. Tao and Sugiura (1992), using dormant buds of D. kaki, noted that if cultures were initiated in BAP, those cultures needed to be transferred to $25 \mathrm{~mm} 6-(\gamma, \gamma$-dimethylallylamino $)$ purine or $3 \mathrm{~mm}$ zeatin to ensure shoot elongation. Shoot cultures were established with nodal stem explants from $D$. virginiana by Palla et al. (2013) in MS medium containing $10 \mu \mathrm{M}$ zeatin.

Contrary to results reported for $D$. kaki in which BAP had little or no effect (Fukui et al., 1989), our results show that, for $D$. crassiflora, BAP medium produced a greater number of shoots per explant than zeatin. BAP promoted multiple shoot formation, whereas cell elongation was limited. BAP has been used to induce budbreak and multiple shoot formation in several woody plant species, such as Balanites aegytiaca (Anis et al., 2010; Khamis et al., 2016), Melia azedarach (Husain and Anis, 2009), Salix tetrasperma (Khan et al., 2011), and Shorea tumbuggaia (Shukla and Sharma, 2017).

Root induction. Shoots derived from explant growing in zeatin did not produce roots in all the treatments (data not shown). Shoot explants grown in medium supplemented with BAP failed to produce roots in the control medium. IBA alone $(2.5-19.6 \mu \mathrm{M})$ did not induce roots (data not shown). Root induction was observed, however, when IBA was supplemented with $396.5 \mu \mathrm{M}$ PG. The greatest frequency of root formation $(79 \%)$ and root length $(2.8 \pm 0.18 \mathrm{~cm})$ was obtained in half-strength MS medium containing $396.5 \mu \mathrm{M}$ PG and 14.2 $\mu_{\mathrm{M}}$ IBA (Table 2). When rhizogenesis was observed, the number of roots induced per explant was always limited to one tap root without secondary root hairs. This root displayed a characteristic black color similar to the taproot produced from seed-grown plants (Fig. 2). A positive rooting response using $\mathrm{PG}$ and IBA has been reported for several tree genera, including Diospyros, Malus (Dobránszki and Teixeira da Silva, 2010), Prunus (Hammatt and Grant, 1997), Jatropha (Daud et al., 2013), and Juglans (Licea-Moreno et al., 2015). 

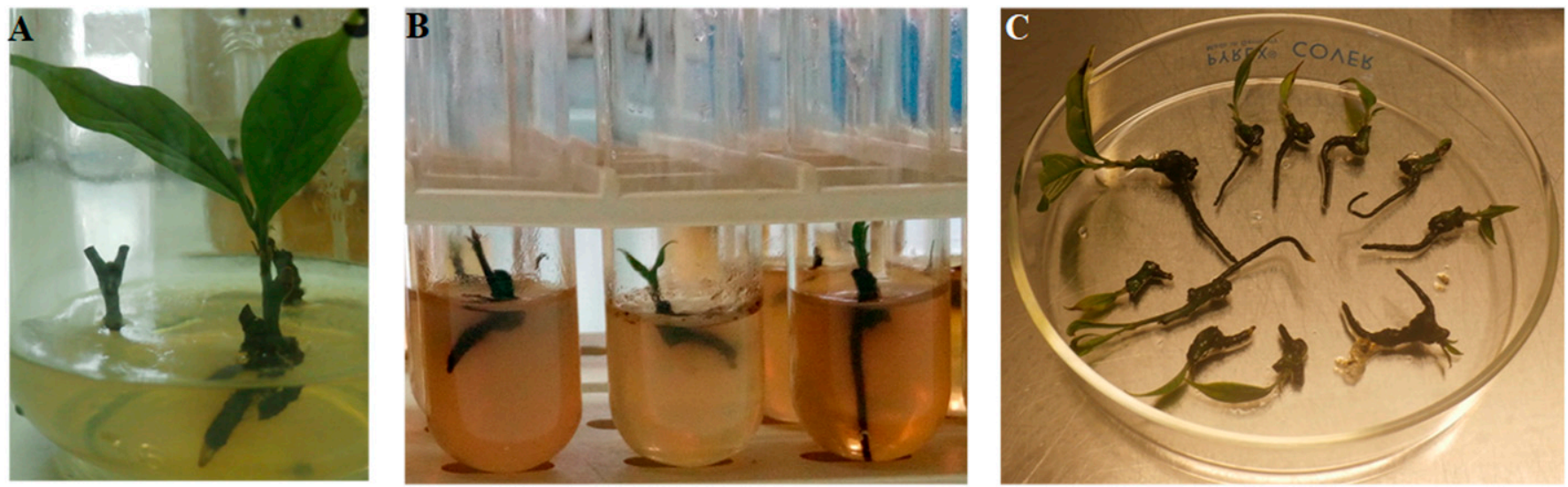

Fig. 2. Root induction in D. crassiflora plants cultured in various media. (A) Shoot in half-strength MS medium with $14.7 \mu \mathrm{M}$ indole-3-butyric acid (IBA) +396.5 $\mu \mathrm{M}$ phloroglucinol (PG). (B) Shoot in half-strength MS medium with 19.6 $\mu \mathrm{M} \mathrm{IBA}+396.5 \mu \mathrm{M}$ PG. (C) Rooted shoots in half-strength MS medium with $14.7 \mu \mathrm{M}$ IBA + 396.5 $\mu_{\mathrm{M}} \mathrm{PG}$.
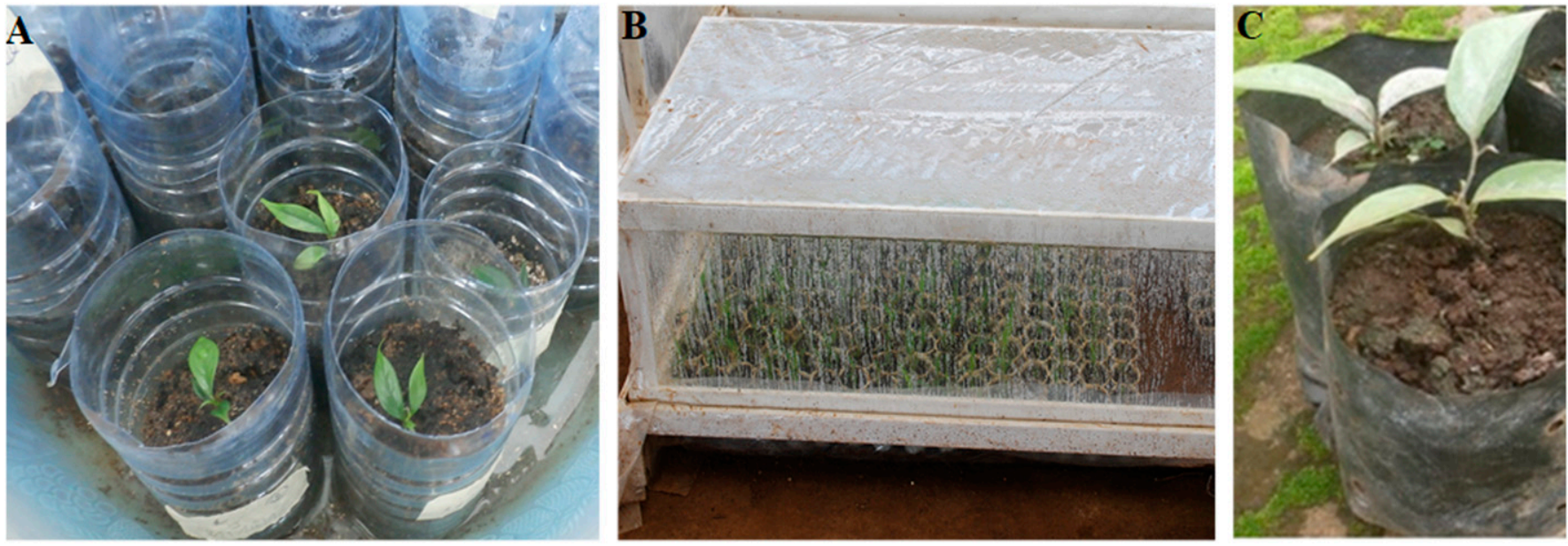

Fig. 3. Potted plantlets of $D$. crassiflora after 12 weeks on rooting medium of $14.7 \mu \mathrm{M}$ indole-3-butyric acid $+396.5 \mu \mathrm{m}$ phloroglucinol followed by 3 months of acclimatization in the greenhouse. Plantlets in culture room (A), mini green house (B), and acclimatized plants $(\mathbf{C})$.

It has been reported that PG acts synergistically with auxin during the most sensitive phase of root initiation (Dobránszki and Teixeira da Silva, 2010; Hammatt, 1994). The application of IBA alone did not result in root formation. Our results show that, in D. crassiflora, PG seems to be essential to induce root formation in the presence of an auxin (IBA, in our case). This confirms the view that PG is an auxin promoter (Daud et al., 2013; Pérez et al., 2016; Teixeira da Silva et al., 2013). A greater percentage of rooting of $D$. virginiana hybrid Rosseyanka (91\%) was also achieved in MS medium containing $5 \mu \mathrm{M}$ IBA and $0.1 \mathrm{~g} \cdot \mathrm{L}^{-1}$ PG (Palla et al., 2013).

Acclimatization. A major limitation in the application of micropropagation technology is high mortality experienced by in vitro-raised plants during laboratory-to-land transfer. When transferred ex vitro, micropropagated plants are exposed to conditions (altered temperature, light intensity, and water stress) that necessitate acclimatization for successful plantlet establishment and survival (Chandra et al., 2010; Kumar and Rao, 2012). The success of $D$. crassiflora acclima- tization was one of the fastidious steps during our micropropagation process. All the in vitro plantlets displayed one black tap root without hair roots, which could explain their slow growth. Fifty rooted plants of $D$. crassiflora derived from different IBA and PG treatments were combined for acclimatization. They resumed their growth after 12 weeks of culture in an ambient growth condition (Fig. 3). The survival rate after 14 weeks was $50 \%$.

\section{Conclusion}

This is the first report describing in vitro propagation of $D$. crassiflora through internode explants. Half-strength MS supplemented by zeatin was effective for shoot elongation and callus formation whereas BAP supplementation was effective for multiple shoot stimulation and development. PG had a positive effect on rooting and acclimatization of rooted shoots. The results obtained confirm that the micropropagation of African ebony is possible, opening up opportunities for domestication of the species and rapid multiplication to meet the demands of conservation efforts.

\section{Literature Cited}

Anis, M., A. Varshney, and I. Siddique. 2010. In vitro clonal propagation of Balanites aegyptiaca (L.). Del. Agrofor. Syst. 78:151-158

Bongjoh, C.A. and M. Nsangou. 2001. Gap disturbance regimes and regeneration dynamics of commercial timber tree species in a southern Cameroon forest, p. 112-124. In: "Sustainable Forest Management of African Rain Forest", Part II Symposium. The Tropenbos Foundation, Wageningen, The Netherlands.

Chandra, S., R. Bandopadhyay, V. Kumar, and R. Chandra. 2010. Acclimatization of tissue cultured plants: From laboratory to land. Biotechnol. Lett. 32:1199-1205.

Cooper, P.A. and D. Cohen. 1985. Micropropagation of Japanese persimmon (Diospyros kaki). Proc. Intl. Plant Prop. Soc. 34:118-124.

Daud, N., A. Faizal, and D. Geelen. 2013. Adventitious rooting of Jatropha curcas L. is stimulated by phloroglucinol and by red LED light. In Vitro Cell. Dev. Biol. Plant 49:183-190.

Dobránszki, J. and J.A. Teixeira da Silva. 2010 Micropropagation of apple: A review. Biotechnol. Adv. 28:462-488.

Dzoyem, J.P., J. Tangmouo, D. Lontsi, F.X. Etoa, and P.J. Lohoue. 2007. In vitro antifungal activity of extract and plumbagin from the stem 
bark of Diospyros crassiflora Hiern (Ebenaceae). Phytother. Res. 21:671-674.

Fukui, H., M. Sugiyama, and M. Nakamura. 1989. Shoot tip culture of japanese persimmon (Diospyros kaki Thunb.). J. Jpn. Soc. Hort. Sci. 58:43-47.

Hammatt, N. 1994. Promotion by phloroglucinol of adventitious root formation in micropropagated shoots of adult wild cherry (Prunus avium L.). Plant Growth Regulat. 14:127-132.

Hammatt, N. and N.J. Grant. 1997. Micropropagation of mature British wild cherry. Plant Cell Tissue Organ Cult. 47:103-110.

Husain, M.K. and M. Anis. 2009. Rapid in vitro multiplication of Melia azedarach L. (a multipurpose woody tree). Acta Physiol. Plant. 31:765772.

Khamis, G., T. Winkelmann, F. Schaarschmidt, and J. Papenbrock. 2016. Establishment of an in vitro propagation and transformation system of Balanites aegyptiaca. Plant Cell Tissue Organ Cult. 125:457-470.

Khan, M.I., N. Ahmad, and M. Anis. 2011. The role of cytokinins on in vitro shoot production in Salix tetrasperma Roxb.: A tree of ecological importance. Trees 25:577-584.

Kumar, K. and I.U. Rao. 2012. Morphophysiological problems in acclimatization of micropropagated plants in ex vitro conditions: A review. J. Ornam. Hort. Plants 2:271-283.

Leakey, R.R.B., J.F. Mesen, Z. Tchoundjeu, K.A. Longman, J.M. Dick, A. Newton, A. Martin, J. Grace, R.C. Munro, and P.N. Muthoka. 1990. Low technology techniques for the vegetative propagation of tropical trees. Commonwealth For. Rev. 69:247-257.

Lemmens, L., D. Louppe, and A.A. Oteng-Amoako. 2012. Ressources végétales de l'Afrique tropicale. Fondation PROTA, Wageningen, The Netherlands.

Licea-Moreno, R.J., A. Contreras, A.V. Morales, I Urban, M. Daquinta, and L. Gomez. 2015. Improved walnut mass micropropagation through the combined use of phloroglucinol and FeEDDHA. Plant Cell Tissue Organ Cult. 123:143154.

Mangiafico, S.S. 2015. An R companion for the handbook of biological statistics: Version 1.09j. Rutgers Cooperative Extension, New Brunswick, NJ.

Mitrofanova, I.V. and O.V. Mitrofanova. 2004. Development of recipient system of woody subtropical plants in vitro. Acta Universitatis Latviensis Biol. 676:189-196.

Morel, G. and R.H. Wetmore. 1951. Fern callus tissue culture. Amer. J. Bot. 38:141-146.

Murashige, T. and F. Skoog. 1962. A revised medium for rapid growth and bioassays with tobacco tissue culture. Physiol. Plant. 15:473-497.

Palla, K.J., R.R. Beasley, and P.M. Pijut. 2013. In vitro culture and rooting of Diospyros virginiana L. HortScience 48:747-749.

Pérez, L.P., Y.P. Montesinos, J.G. Olmedo, R.B. Rodriguez, R.R. Sánchez, O.N. Montenegro, R.C.R. Escriba, D. Daniels, and R. GómezKosky. 2016. Effect of phloroglucinol on rooting and in vitro acclimatization of papaya (Carica papaya L. var. Maradol Roja). In Vitro Cell. Dev. Biol. Plant 52:196-203.
Pijut, P.M. 2012. In vitro propagation of tropical hardwood tree species: A review (2001-2011). Propag. Ornam. Plants 12:25-51.

Schatz, G.E., I. Lowry, J.M. Onana, T. Stévart, and V. Deblauwe. 2019. Diospyros crassiflora. The IUCN Red List of threatened species 2019. E.T33048A2831968. 14 Sept. 2019. <http:// dx.doi.org/10.2305/IUCN.UK.2019-1.RLTS. T33048A2831968.en>.

Shukla, S.P. and A. Sharma. 2017. In vitro seed germination, proliferation, and ISSR markerbased clonal fidelity analysis of Shorea tumbuggaia Roxb.: An endangered and high trade medicinal tree of Eastern Ghats. In Vitro Cell. Dev. Biol. Plant 53:200-208.

Tangmouo, J.G., A.L. Meli, J. Komguem, V. Kuete, F.N. Ngounou, D. Lontsi, V.P. Beng, M.I. Choudhary, and B.L. Sondengam. 2006. Crassiflorone, a new naphthoquinone from Diospyros crassiflora (Hien). Tetrahedron Lett. 47:3067-3070.

Tao, R. and A. Sugiura. 1992. Micropropagation of Japanese persimmon (Diospyros kaki L.), p. 424-440. In: Y.P.S. Bajaj (ed.). High-tech and micropropagation II. Springer, Berlin.

Taylor, B. 2012. A developing story. Wood\&Steel 72:5.

Teixeira da Silva, J.A., J. Dobránszki, and S. Ross. 2013. Phloroglucinol in plant tissue culture. In Vitro Cell. Dev. Biol. Plant 49:1-16.

Tsobeng, A., Z. Tchoundjeu, L. Kouodiekong, and E. Asaah. 2011. Effective propagation of Diospyros crassiflora (Hiern) using twig cuttings. Intl. J. Biosci. 1:109-117. 